\title{
The Objective Assessment of Cataract
}

\author{
NICHOLAS A. P. BROWN, ANTHONY J. BRON, WILLIAM AYLIFFE, JOHN \\ SPARROW and ADRIAN R. HILL \\ Oxford
}

\begin{abstract}
Summary
The objective assessment of cataract is central to any epidemiological or therapeutic study of cataract. The objective methods consist of:

1: A resolution target projection ophthalmoscope (Acuity scope) for the estimation of potential visual acuity.

2: The Oxford Clinical Cataract Classification and Grading System, which records and quantifies the features of the lens that are visible at the slit-lamp microscope. This system is essential since photographic methods cannot define the morphology of cataract.

3: Two photographic methods; slit-lamp photography and retro-illumination photography are needed to give a comprehensive statement about the amount of cataract. The negatives are measured by computerised image analysis systems.
\end{abstract}

The objective assessment of cataract is central to any epidemiological or therapeutic study of cataract and has become a priority since the arrival of drugs that may have a beneficial effect on cataract. ${ }^{1,2}$

To the patient, the subjective assessment of their own vision provides the most relevant estimate of the effects of cataract, but this is the parameter that is least reliably assessed by the clinician and most readily influenced by factors unrelated to the cataract. In spite of this, visual acuity testing, including testing with low contrast targets, is a necessary part of cataract assessment.

To the clinician, the objective methods of assessment are at a priority in estimating cataract. The methods used include resolution target projection ophthalmoscopy (acuity scope), clinical cataract classification and grading and two photographic techniques. These techniques are best used together to give a comprehensive statement about the cataract, but if time and expense are limited, users may restrict their choice to parts of the system.

\section{Objective Assessment of Visual Acuity} (Acuity Scope)

Resolution Target Projection

\section{Ophthalmoscope}

The image degrading effect of cataract is assessed with a resolution test target projection ophthalmoscope as first described by Cotlier in 1981.,4 His instrument projected a standard USAF 3 bar resolution test chart, which we have modified in the instrument now made for us by Keeler, with the elimination of those bars from the target which were too large or too small to be relevant. The new target is presented in a logarithmic progression of sizes for better numerical assessment (Fig. 1). The projected image is degraded by the cataract both in the projection and in visualisation. The pupil is first dilated. The observer directs the instrument into the fundus by observing a retinal blood vessel, adjusts the focusing control until it is accurately focused. The projected target is then directed towards the posterior pole of the eye and the smallest 3 bar target in which both 


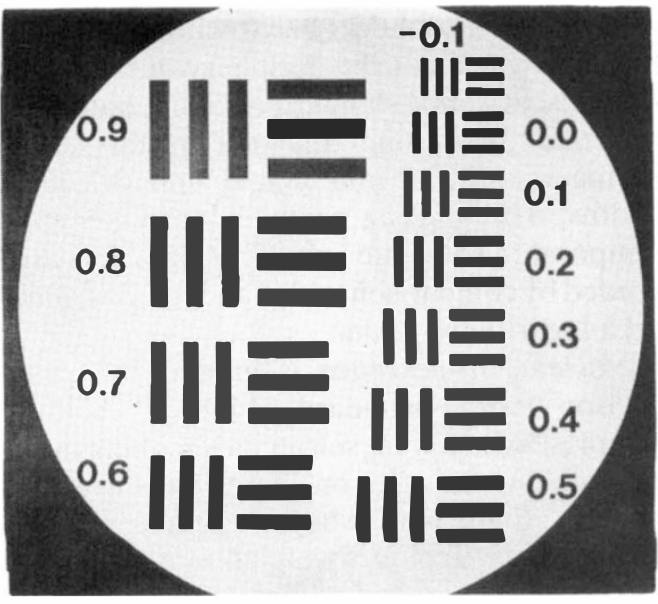

Fig. 1. Resolution target projection ophthalmoscope (Acuity scope). Three bar targets in logarithmic progression with equivalent logarithmic visual acuity scores. horizontal and vertical bars are identifiable is recorded.

\section{The Oxford Clinical Cataract Classification and Grading System}

A standardised system of cataract classification and grading at the slit-lamp microscope is basic to any in vivo cataract study. The morphological classification of cataract is important since different morphological types of cataract behave in different ways and the morphology is better identified by the clinician using a slit-lamp than by studying photographs. The numerical grading of opacity is more accurately performed by photographic systems, but these techniques lack the ability to grade for individual morphological features, so that the clinical grading system is still relevant in units possessing advanced photographic techniques. In units lacking photographic systems, the Oxford clinical classification and grading system can be

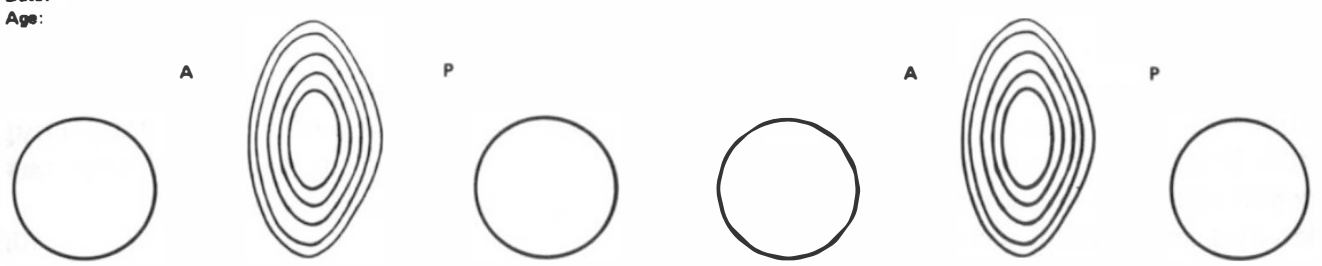

\begin{tabular}{|c|c|c|c|c|c|c|c|c|c|c|c|c|c|c|c|}
\hline Feature Zone & $c_{1}$ & $c_{2}$ & $c_{3}$ & $C_{4}$ & $\mathbf{N}$ & $\begin{array}{l}\text { PROOECTION } \\
\text { OPHTHALMOSCOPE }\end{array}$ & $\begin{array}{l}\text { PUP } \\
\text { SIZ }\end{array}$ & & Fenture Zone & $c_{1}$ & $c_{2}$ & $c_{3}$ & C4 & $\mathbf{N}$ & $\begin{array}{l}\text { PROAECTION } \\
\text { OPHTHALLOSOSOPE }\end{array}$ \\
\hline THICKNESS & & & & & & & $\mathrm{mm}$ & $\mathrm{mm}$ & THICKNESS & & & & & & \\
\hline ASC & & & & & & CATARACT TYPE & & & ASC & & & & & & CATARACT TYPE \\
\hline $\begin{array}{c}\text { CORTICAL } \\
\text { SPOKES }\end{array}$ & & & & & & & & & $\begin{array}{c}\text { COATICAL } \\
\text { SPOKES }\end{array}$ & & & & & & \\
\hline WATERCLEFTS & & & & & & & & & WATERCLEFTS & & & & & & \\
\hline VACUOLES & & & & & & & & & VACUOLES & & & & & & \\
\hline RETRO-DOTS & & & & & & & & & RETRODOTS & & & & & & \\
\hline PSC & & & & & & & & & PSC & & & & & & \\
\hline FOCAL DOTS & & & & & & LEMS STATUS & & & FOCAL DOTS & & & & & & LEMS STATUS \\
\hline BRUNESCENCE & & & & & & & & & ERUNECEEMCE & & & & & & \\
\hline $\begin{array}{l}\text { WHITE } \\
\text { SCATTER }\end{array}$ & & & & & & & & & MCATTER & & & & & & \\
\hline $\begin{array}{l}\text { OTHER } \\
\text { FEATURES }\end{array}$ & & & & & & & & & $\begin{array}{l}\text { OTMER } \\
\text { FEATUAES }\end{array}$ & & & & & & \\
\hline
\end{tabular}

Fig. 2. The Oxford Clinical Cataract Classification and grading system score card. 
applied on its own. We hope that this system will come to be regarded as standard and we are happy to provide it for use in other units.

Earlier cataract grading systems related to specific types of cataract ${ }^{5,6,7}$ and later systems have been more comprehensive..$^{4,8,9,10,11,12,13,14}$ The basis of our system was first described in 1983 and since then we have gained experience with the system and have incorporated modifications which give rise to the system described here, ${ }^{15}$ which will not be further modified. Brief details of the system are:

The features of cataract that are graded are: Anterior clear zone thickness, anterior subcapsular opacity, posterior subcapsular opacity, cortical spoke opacity, waterclefts, vacuoles, retro-dots, focal dots, nuclear brunescence and white nuclear scatter. Each feature is graded on a $0-5$ scale, the result being recorded on a grading chart (Fig. 2).

A grading booklet is fixed to the slit lamp microscope head support pillar and presents grading diagrams to the observer at the same angular magnification as that of the object being graded when viewed by the microscope. The use of the booklet and grading chart ensures a standard order of examination.

The anterior subcapsular clear zone is significant in cataract formation ${ }^{16}$ and is demonstrated with a narrow slit-beam. It is graded by comparison with diagram showing different widths (Fig. 3). Anterior and posterior subcapsular opacities are commonly roughly circular and are graded according to diameter (Fig. 4). When the opacity is not circular, it is mentally 'rounded up' and graded. Cortical spoke (Cuneiform) opacities are typically radial base-out wedge segments and are graded by the area affected in 'pie shaped segments'. When the opacities occupy nonadjacent segments, these are apposed in the 'minds eye' and the overall area guaged by comparison with the standard diagram (Fig. 5). Waterclefts have a radial configuration and are graded in the same way. Vacuoles are graded according to their frequency within an $8 \mathrm{~mm}$ diameter area by comparison with standard diagrams showing frequency on a logarithmic scale (Fig. 6). Retro-dots are small rounded opacities in the deep cortex, best seen with retro-illumination and are graded within a $6 \mathrm{~mm}$ diameter circle in the same way as vacuoles. Focal dots occur with increasing frequency towards the periphery of the lens. For this reason a standard 'grading patch' is selected by setting the slit beam focal illumination to $2 \mathrm{~mm}$ height and $0.7 \mathrm{~mm}$ widths. The grading patch is located $3 \mathrm{~mm}$ temporal to the optic axis. The focal dots are graded by comparison with standard diagrams on a logarithmic scale.

Nuclear brunescence is graded by comparison with standard Munsell colour sample ${ }^{18}$ which were selected by making multiple colour matches on lenses with brunescence, following which evenly spaced representative colours were chosen. The lens brunescence is graded by matching to the closest representative colour of the five sample colours provided. ${ }^{19}$ White nuclear scatter is obvious when it occurs in isolation, but more commonly coexists with brunescence, which complicates the assessment slightly. Grading is performed by comparison with Munsell neutral density grey scale samples to select the closest match. To reduce the confusing effect of brunescence both the lens being graded and the Munsell neutral density patches are viewed through the same yellow filter (Wratten 12).

Other lens features are recorded when present including lamellar separation, coronary opacities, lamellar opacity, sutural opacity, pseudo-exfoliation, polychromatic lustre, but these features are not graded.

\section{Photographic Techniques}

The ideal would be a single photographic technique that could give all the necessary information, but unfortunately this is not possible, and it is necessary to use two. Slitimage photography (Fig. 7), as developed by Niesel, ${ }^{20}$ and Brown ${ }^{21}$ gives useful information concerning the dimensions and optical densities of an axial section of the lens. From the negatives made by this technique, it is possible to measure the dimensions and densities of any opacities that lie in the plane of the section, but other opacities are missed altogether. This information loss can be reduced by Hockwin's ${ }^{22}$ method in which the slit-image camera is made to rotate about a horizontal axis, so that multiple images can be made of the same lens. However, this still 


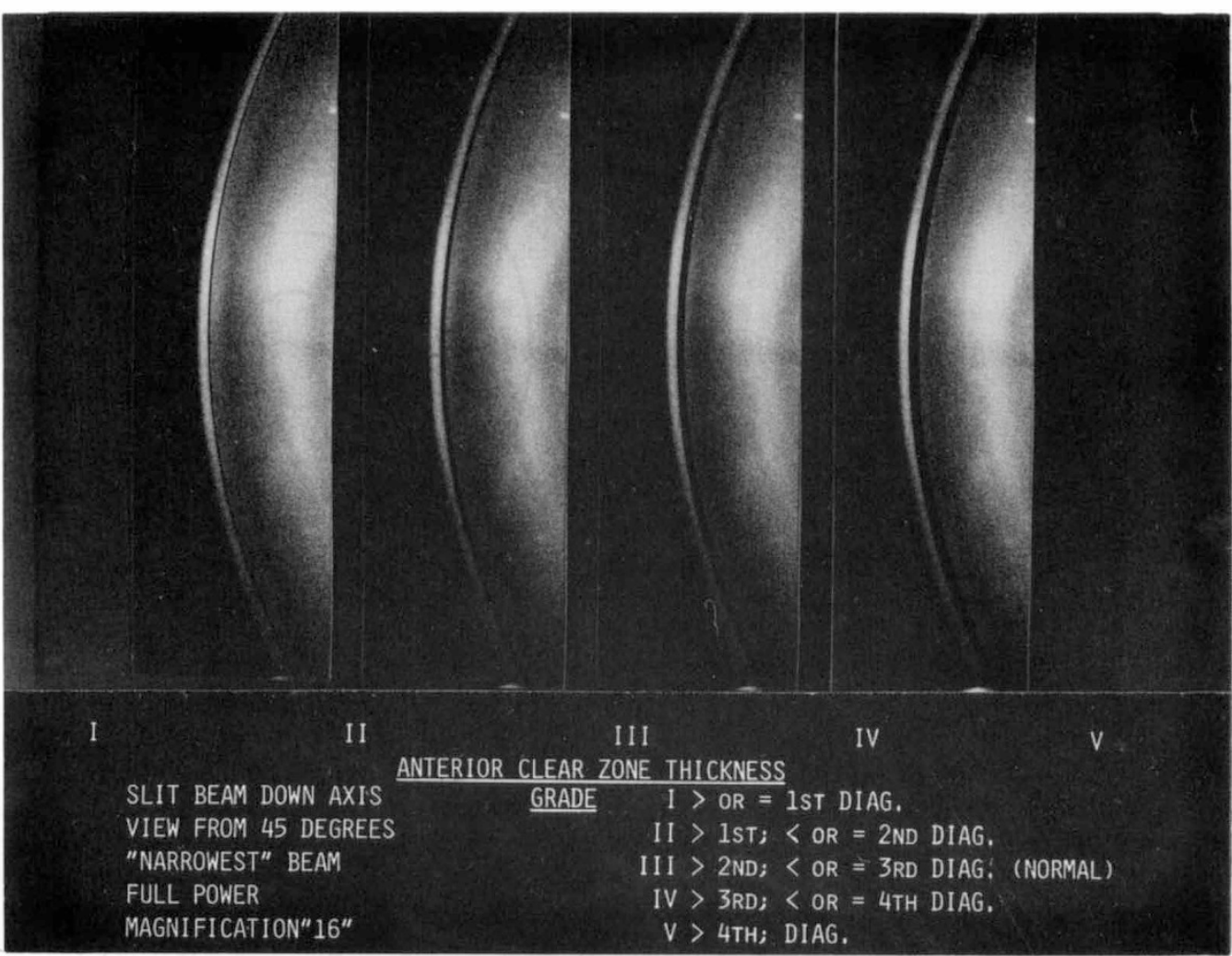

Fig. 3. Grading diagram for estimating the width of the subcapsular clear zone of the lens at the slit-lamp microscope.

gives an incomplete statement about the total amount of cataract present in a lens.

The nucleus is well demonstrated by the slit-image, so that nuclear sclerosis is measured best by this technique ${ }^{23,24}$ and it is in respect to the cortex that the technique is inadequate, so that investigators may prefer to limit slit-image photography to examination of the nucleus alone. ${ }^{25}$ Another source of error is the shadow area that lies behind an opacity, which prevents information being obtained from these areas. Slit-image photography does give other additional useful information concerning the dimensions and optical densities of non-cataractous regions of the lens, which vary from the normal in such conditions as diabetes.

Retro-illumination photography (Fig. 8) gives a useful statement of the total amount of cortical cataract that is present in a lens ${ }^{23,24}$ but demonstrates nuclear sclerosis poorly. It gives little information about the density of the opacity and no information about the densities of non-cataractous areas of the lens. Slitimage photography and retro-illumination photography need to be used in conjunction to assess the state of the lens with cataract, and this is also the finding of other workers. ${ }^{23,24}$

To obtain further information at a molecular level, laser spectroscopy ${ }^{26}$ may be the preferred method and it may be possible to estimate changes in lens fibre dimensions by specular photography. ${ }^{27,28}$

\section{Retro-Illumination Photography}

Fincham ${ }^{2}$ used a 45 degree glass plate as a mirror to allow simultaneous axial illumination and photography of the lens. The information loss due to the corneal reflex can be avoided by using the Zeiss Photo slit-lamp and taking pairs of pictures of each lens with the light projected into the eye from the right and then from the left. ${ }^{30}$ The images from left to 
ASC \& PSC OPACITIES

PUPIL SMM

MAGNIFICATION "10x"

FOCAL \& RETRO-ILLUMINATION

$\underline{\text { GRADE }}$

$$
\begin{aligned}
& \text { 0: FEATLRE ABSENT } \\
& \text { I }:>0 ;<O R=\text { CIRCLE I } \\
& \text { II }:>1 ;<O R=\text { CIRCLE } 2 \\
& \text { III }:>2 ;<O R=\text { CIRCLE } 3 \\
& \text { IV }:>3 ;<O R=\text { CIRCLE } 4 \\
& \text { V }:>C I R C L E 4
\end{aligned}
$$

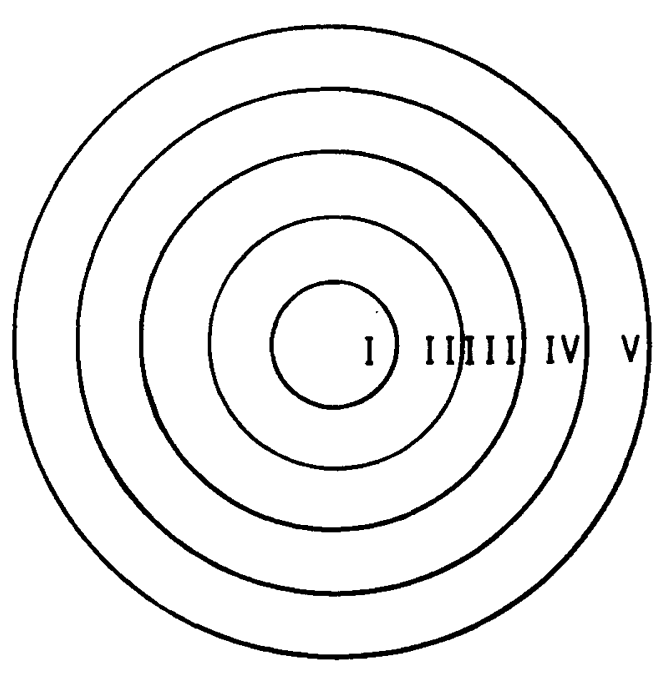

DIAMETER SCALE

Fig. 4. Grading diagram for estimating the extent of subcapsular cataract.

SPOKE OPACITIES AND WATERCLEFTS

PUPIL 8MM

MAGNIFICATION "10x"

ANT \& POST SUPERIMPOSED

FOCAL \& RETRO-ILLUMINATION

GRADE

$$
\begin{aligned}
& \text { 0: FEATURE ABSENT } \\
& \text { I }:>0 ;<0 R=1 \text { PIE } \\
& \text { II }:>1 ;<0 R=2 \text { PIES } \\
& \text { III }:>2 ;<0 R=3 \text { PIES } \\
& \text { IV }:>3 ;<0 R=4 \text { PIES } \\
& \text { V }:>4 \text { PIES }
\end{aligned}
$$

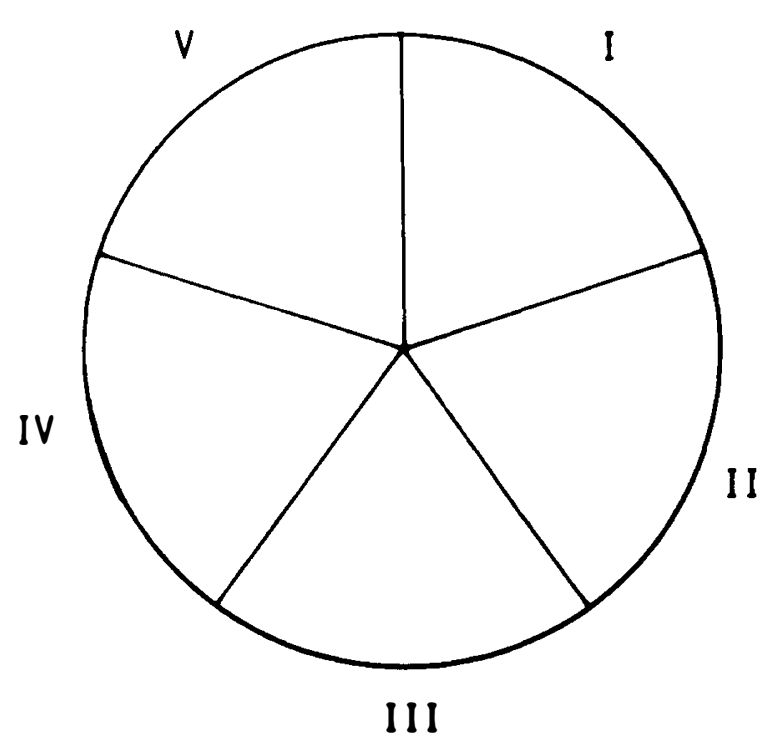

"PIE" SEGMENTS

Fig. 5. Grading diagram for estimating the extent of cortical spoke cataract. The same method is used to estimate the extent of water clefts. 


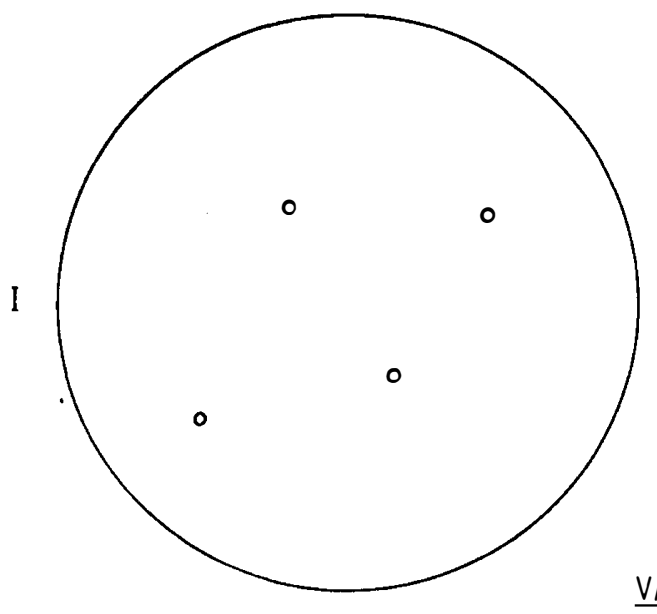

RETRO-I LLUMINATION PUPIL 8MM DIAMETER

VACUOLES

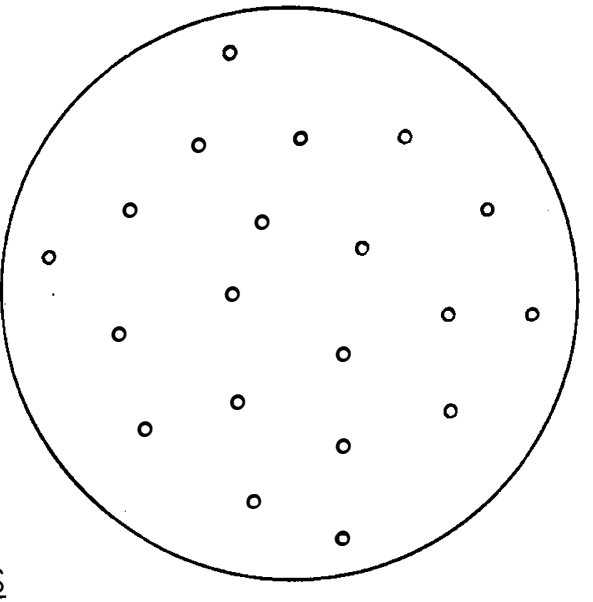

GRADE

0 : FEATURE ABSENT

I : >0; $\angle O R=1 S T$ DIAG.

II $:>1 S T ;<O R=2 N D D I A G$.

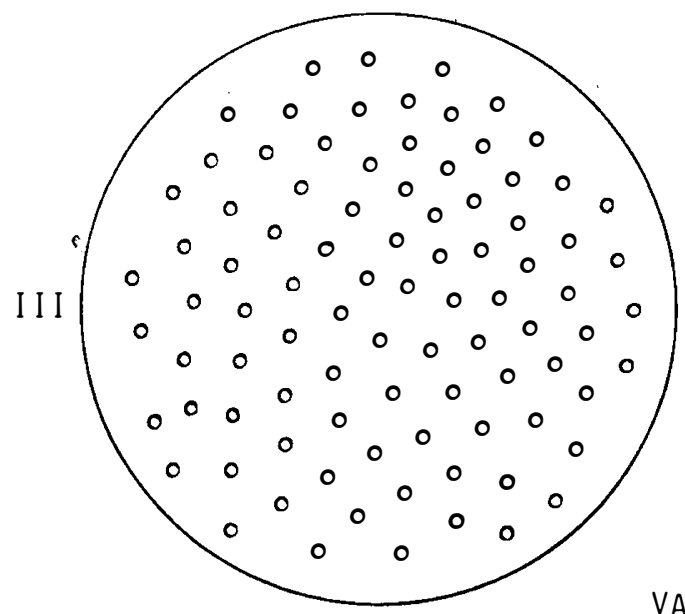

VACUOLES

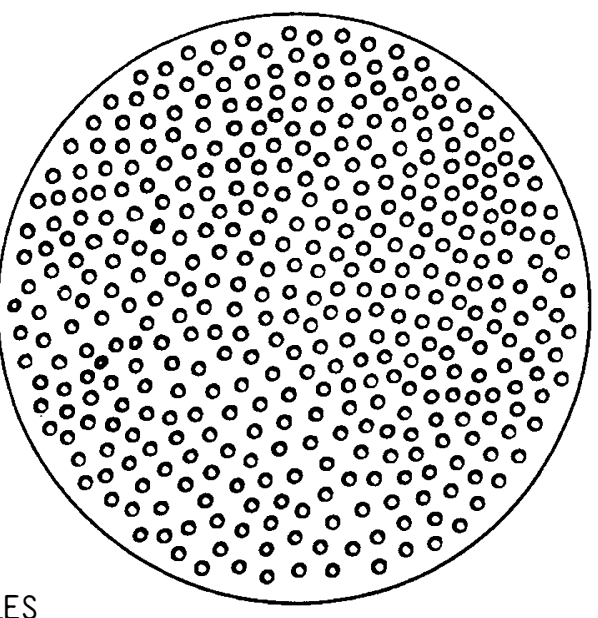

GRADE

RETRO-I LLUMINAT ION

III: > 2ND; < OR = 3RD DIAG.

PUPIL 8MM DIAMETER

IV : > 3RD; $<O R=4 T H D I A G$.

$\mathrm{V}:>4 \mathrm{TH}$ DIAG.

Fig. 6. Grading diagram for estimating the amount of vacuoles within the lens. A similar method is used to estimate the amount of retro-dot cataracts.

right halves of each lens have then to be matched and measured. Clearly a single image without a reflex is the more convenient.

Our system of retro-illumination photo- graphy (Fig. 9) uses an apparatus based on the Fincham principle with the corneal reflex cancelled by crossed polarised filters, as described by Kawara. ${ }^{31,32}$ The apparatus is fit- 


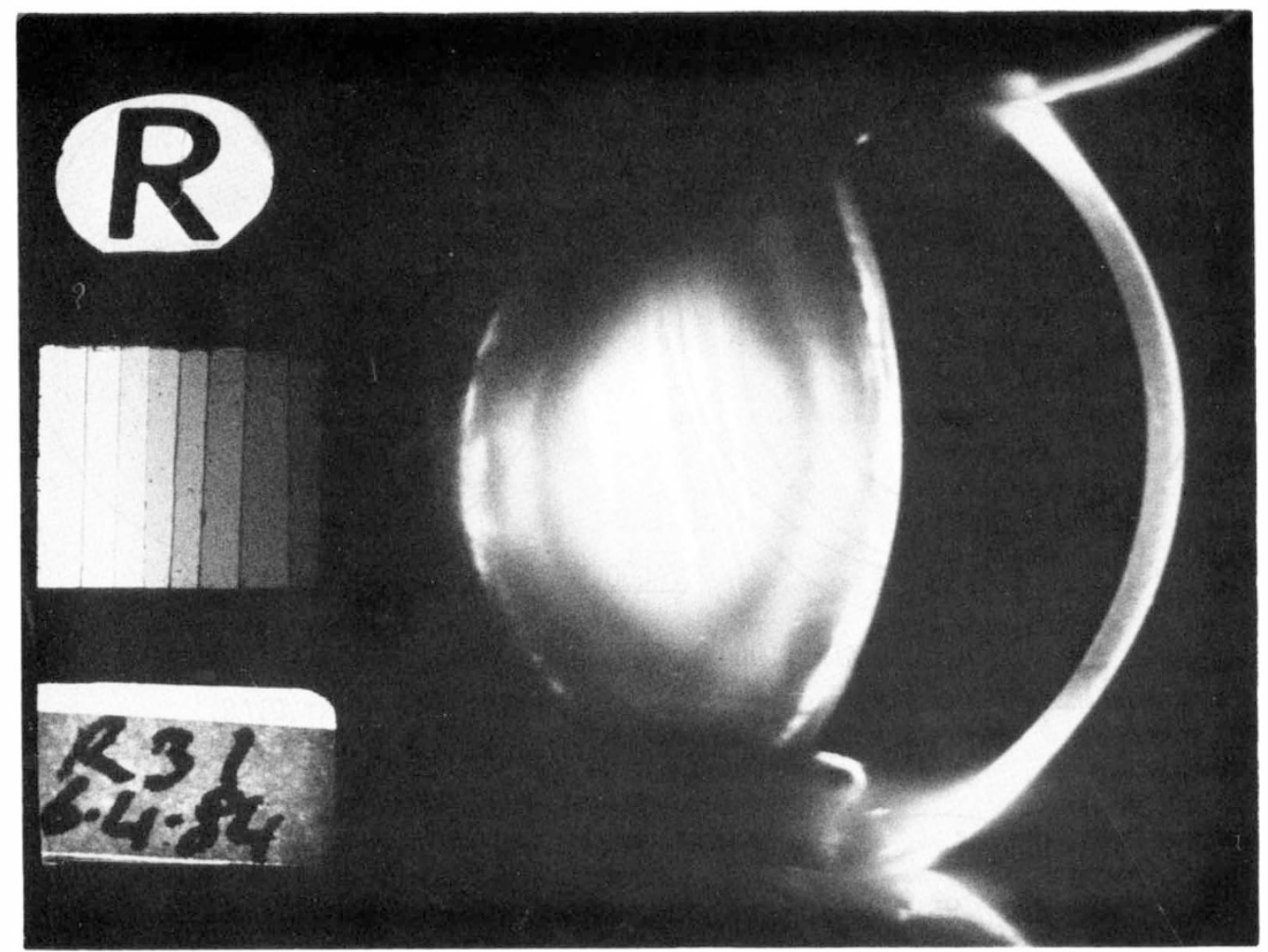

Fig. 7. Slit-image picture of a lens with cortical and nuclear cataract.

ted to the projector of a Zeiss Photo Slit Lamp and replaces the camera supplied with that instrument. An $80 \mathrm{~mm}$ focal length objective is used to give as much magnification as possible (1.9:1). The use of a conventional photographic lens has the advantage that depth of field can be maximised. The most useful lens aperture has been found to be $\mathrm{f} 11$, which gives an adequately bright view-finder image, when a photomicrographic screen is used in the camera.

Contrast is improved with an orange filter, similar in colour to the reflected light from the fundus. A Wratten 22 filter is placed in the projector light path. It was noted that the residual light from the corneal reflex that manages to pass the crossed polarised filters is in the blue part of the spectrum, as is the light scattered in the cornea by birefringence. Thus the orange filter reduces the corneal interference with image quality.

Accurate and repeatable alignment techniques are important in retro-illumination photography, as they are with slit-image photography, so that sequential pictures of the same eye can give valid comparisons. Kawara $^{32}$ advised directing the camera so that the optic disc was centred behind the lens of the eye to give maximum retro-illumination. Our experience showed that this could be achieved by manoeuvring a fixation light before the patient's other eye and the photographer could identify the position of maximum image brightness. However, it was not easy to return to the same position on each occasion and small movements of the patient's eye caused large fluctuations in the level of retro-illumination. The present system uses fixation lights on either side of the glass plate reflector at the front of the camera. As with the slit-image camera, there is one light for each eye. Each light is placed at 15.5 degrees to the side of the camera axis and 1.5 degrees above (measured at the nodal point of the eye), so that in the normal eye the disc will be in line with the camera axis. In eyes with 


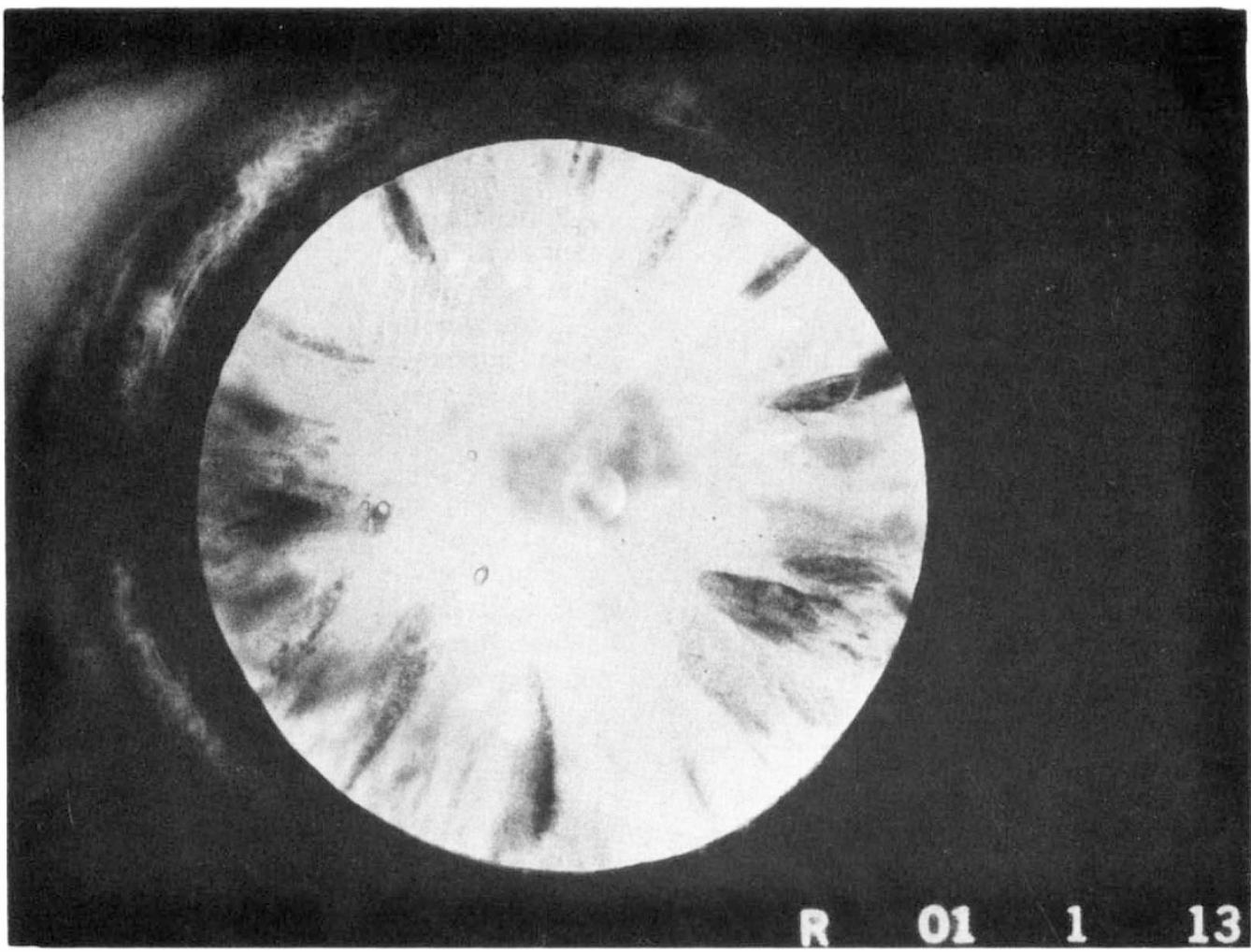

Fig. 8. Retro-illumination picture of a lens with cortical cataract. Both retro-illumination and slit-image pictures are needed to give a reasonably comprehensive statement on the extent of the cataract.

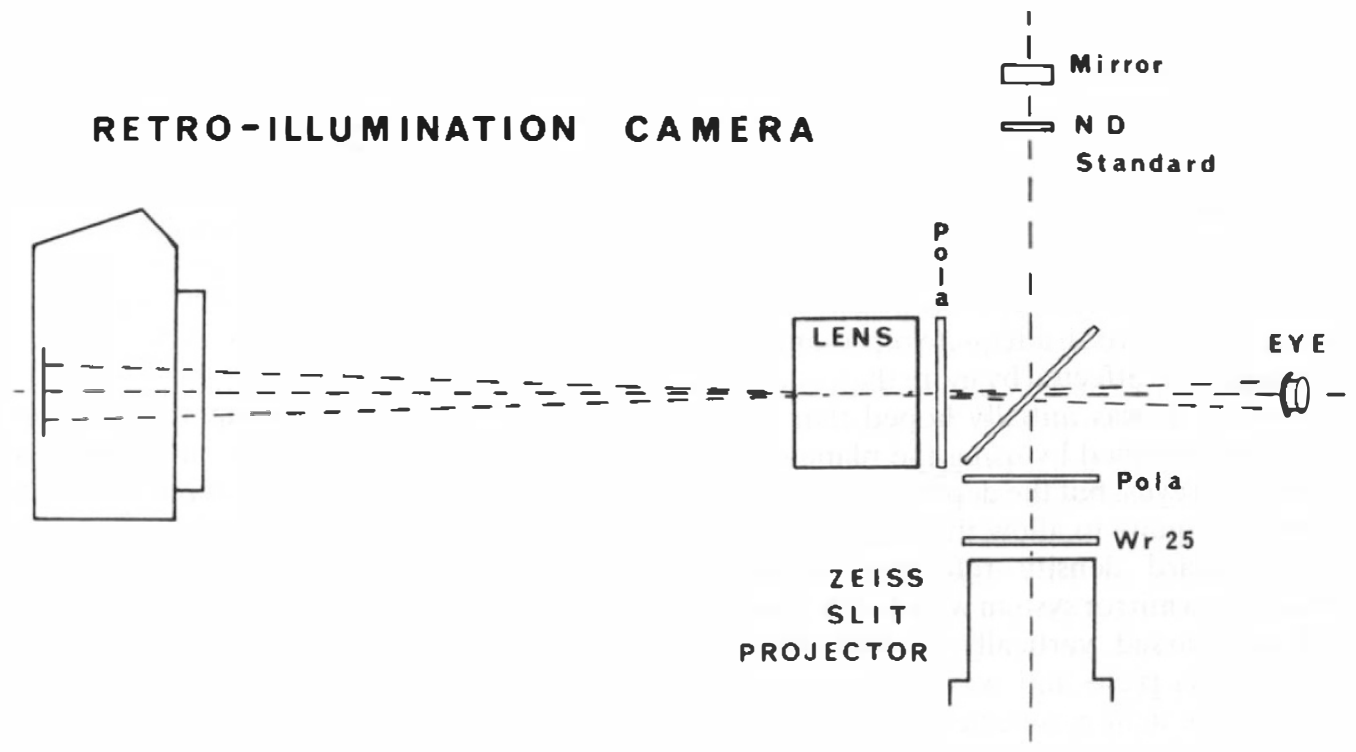

Fig. 9. The optics of the retro-illumination camera. 


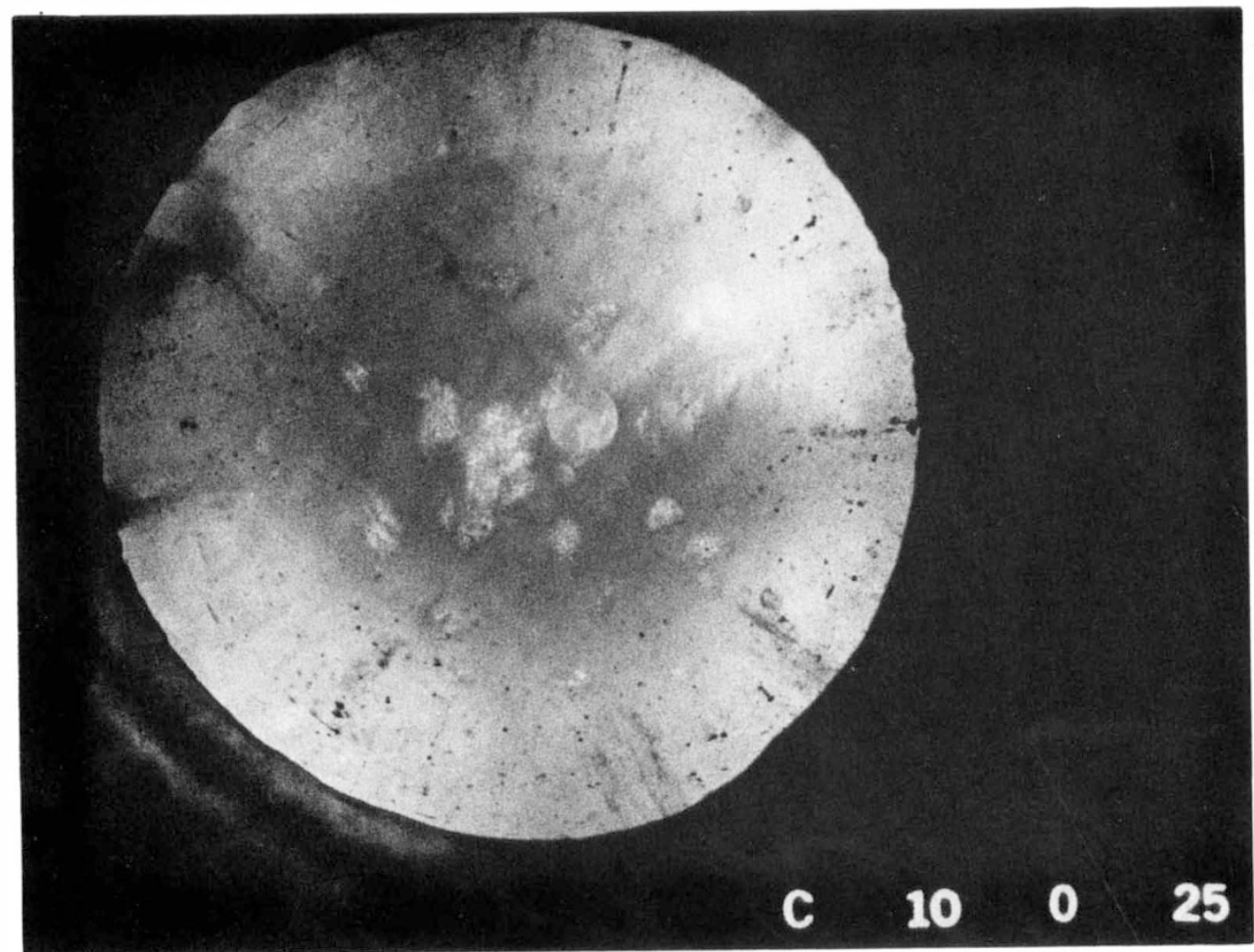

Fig. 10. Retro-dot cataracts show birefringence in the polarised light of the retro-illumination camera.

abnormal dimensions the disc serves as a partially effective reflector and, more importantly, in a manner that is accurately repeatable. The fore and aft positioning is controlled by focusing the viewfinder image in the plane of the most significant part of the cataract. Most usually this is seen to be the anterior cortex, or the posterior subcapsular region. The plane of focus that is chosen is noted for future examinations of the same eye. Occasionally two separate planes of focus are needed to give an adequate representation of a single lens affected by more than one type of opacity. It was initially hoped that focus could be simplified by using the plane of the pupil for all eyes, but the depth of field has not proved adequate to allow this.

A standard density reference is incorporated by a mirror system which collects light that has passed vertically through the 45 degree glass plate and would otherwise be wasted. The light is reflected twice to turn it back through 180 degrees to where it passes through an ND 0.6 step standard density in the plane of focus of the camera. This standard density allows correction for variations in film, development and flash light output, but no allowances can be made for the variability of fundal reflection, which differs considerably between individuals. The accurate alignment of the patient's eye with the camera ensures that there will be no significant variation in fundal illumination between separate frames, but changes in the amount of cataract with time will cause changes in the fundal illumination.

The images show any opacities in the lens in strong silhouette (Fig. 8). The one exception appears to be the retro-dot cataract ${ }^{17}$ which sometimes produces a bright image by birefringence of the polarised light (Fig. 10). This must introduce a small error into image measurement. Nuclear sclerosis is not well demonstrated.

\section{Slit Image Photography}

The instrument now used is based on that 
described by Brown ${ }^{33,34}$ and is built on a onepiece solid plate chassis with its own slit-projector in place of the Zeiss slit-projector of the previously described instrument. The camera utilises Scheimpflug's principle to eliminate the depth of field problem with a tilted film plane. The relatively high magnification of $1.75: 1$ vertically and $2: 1$ horizontally is identical to that of the first model. The same system of density standardisation is used.

Precise alignment with the patient's eye is essential if results are to be repeatable. The present instrument has one significant modification from that previously described. This is a fibre optic bundle which passes from the centre line of the front plate of the slit-projector to the camera viewfinder. The patient fixates a pinpoint fixation light that is displaced 5 degrees (the normal angle $\alpha$ ) from the axis of the slit beam. When the patient's eye is correctly aligned with the apparatus, the light reflected from the cornea falls on the centre line of the slit-projector and illuminates the fibre optic bundle. The photographer can then see the other end of the fibre optic bundle illuminated in the viewfinder and judge whether the apparatus is mis-aligned, nearly correctly aligned, or exactly aligned. The vertical and antero-posterior alignments are controlled by cross-hairs in the viewfinder, as previously described. The photographer now has control of all the alignments visible in the viewfinder up to the moment of releasing the camera foot switch.

Similarly, strict alignments are built into the instrument developed by Hockwin, ${ }^{22}$ in which a photo-electric sensor connected to a speaker gives audible information on horizontal alignment, for which the fibre optic bundle serves in our system.

\section{The Image and its Analysis}

The film used is Ilford XP1 monochrome film, which is chosen because of its extended density range and fine grain. The density range of conventional film is able to more than cover the full range of densities found in the healthy lens, but fails to cope with the densities met in cataract, since maximum density is quickly reached. A change in density in a cataract, which is in the range that exceeds the film's maximum density, will not be identified.
A photographic negative of the lens contains a vast quantity of information on dimensions and densities. Forward planning is needed to decide what is most relevant in order to avoid the collection and storage of huge quantities of data of little value.

In the analysis of retro-illumination negatives we have limited ourselves to answering just one question, namely the percentage of the pupil area that is occupied by cataract. The slit-image negatives are measured only on the optic axis to give information on the density of the clear parts of the lens, and of any cataract that lies on the axis. The sagittal width of the lens and of the identifiable zones of discontinuity, in particular the subcapsular clear zone and the zone of disjunction, are measured. The dimensions are of particular interest in the diabetic lens in which these zones are seen to be expanded in the slitimage negatives ${ }^{35}$ and may change in response to treatment. If the investigator is limited to slit-image negatives, then multilinear analysis, ${ }^{36}$ or area density analysis ${ }^{21,37}$ is desirable and might ideally be performed in all investigations if time and cost permit.

The slit-image negatives have the image of the neutral density step wedge in steps of ND 0.3 . This serves the densitometer to make valid comparisons between the densities in the lens image and in the image of the step wedge regardless of any change in flash output and also to compensate for changes in development of the film which affects the density curve $(\gamma)$ of the negative.

\section{Analysis of the Retro-Illumination Image}

The retro-illumination negatives are measured on a computer image analysis system, which gives a black and white television display of the negative. The degree of enlargement of the negatives is adjusted so that the image of the pupil becomes equal in diameter to a circle of set size on the screen. In instances in which the pupil is somewhat oval, then the smaller diameter of the pupil is made to equal the diameter of the set circle. The lowest detectable density is set to correspond to that of the retro-illumination background in an area of the lens unaffected by cataract. The frequency distribution of grey levels across the reference wedge is computed and 
used to adjust the recorded grey values so that they correspond to a constant scale. The contrast of the image in the set circle is enhanced by displaying the adjusted grey level values as a linear function of the maximum possible range. The area of cataract is then computed as that portion of the image with grey values which lie in the range between the least dense and a value representing two-thirds of the range between the most frequent grey level in the image and the least dense tone.

\section{Analysis of the Slit-Image}

\section{Graticule Measurement}

Dimensional information concerning the widths of the lens, the lens zones and the depth in the lens of cataract is readily obtained without densitometry equipment. A grid system was used previously ${ }^{21}$ to measure the depth of opacities within the lens ${ }^{38}$ to date the onset of cataracts of traumatic and other causes of rapid onset cataract.

The present system has been refined to give more precise measurement. Graticules have been photographed with the slit-image camera with the camera cross hair, which correspond to the position of the anterior pole of the lens, aligned with a mark on the graticule. The resultant negatives were printed onto photographic paper in a Zeiss (Jena) Documator to produce prints that are used for measurement of slit-image negatives when these are inserted into the Documator at the same magnification setting. The previously mentioned mark on the print of the graticule is aligned with the Documator projected image of the anterior pole of the lens. Thus this system of measurement takes into account the magnification of the camera and of the Documator and any distortions present in their optical systems. It does not allow for the effects of the cornea and anterior lens surface on the magnification.

\section{Scanning Densitometry of the Slit Image}

The densitometric data are then processed. The axial measurements are standardised against reference values and film density is converted to a true value. The three scans from each eye are averaged as are the scans from successive exposures of the same eye.
Any slight antero-posterior misalignment of the eyes which may occur between the scans is compensated for by aligning the two sets of data on the anterior surface of the lens before they are combined. All distances are measured from the anterior pole of the lens. The resulting combined data can be displayed in graphical form.

A new generation of cameras is under development that will allow the image to be digitised at the image plane and eliminates the densitometry of negatives.

\section{Repeatability Studies}

Repeatability of the clinical measures has been studied using both intra-observer, assessments. Twenty cataracts were assessed independently by 4 observers, and later second assessments were performed on the same lenses by 2 of the 4 observers. (The time delay between the first and the second observations was on average 51 days.) The data was analysed using the weighted kappa statistic, a chance corrected measure of agreement, which is weighted linearly to penalise increasing observer disparity. ${ }^{39,40}$

\section{(1) Resolution Target Projection Ophthalmoscope}

The intra-observer (within observers) mean weighted kappa value for this instrument was $\mathrm{Kw}=0.71$, and the inter-observer (between observers) mean value was $\mathrm{Kw}=0.69$. These both represent 'good' agreement.

\section{(2) The Oxford Clinical Cataract} Classification and Grading System

The intra-observer mean weighted kappa value for the system as a whole was $\mathrm{Kw}=$ 0.68 , and the inter-observer mean value was $\mathrm{Kw}=0.55$. These values represent 'good' and 'fair' agreement respectively. For the individual feature, the inter-observer $\mathrm{Kw}$ ranged from 0.87 (excellent) to 0.36 (poor). Users of the system should be aware of the interobserver correlation to be expected for the individual features.

\section{(3) Photographic Techniques}

Repeatability studies have been conducted on the retro-illumination and slit-image techniques. Patients with cataract were photo- 
graphed on two successive occasions separated by an interval of up to four weeks. The examinations were performed by different investigations and the film changed between examiners.

The correlation values $\mathrm{r} 2$ for the scanning densitometry of the slit-image negatives of 27 paired examinations varied from 0.51 (fair) to 0.99 (excellent) with a mean value of 0.90 (excellent). Results of the retro-illumination negatives are awaited and expected to be similar.

\section{References}

${ }^{1}$ Kador PF: Overview of the current attempts toward medical treatment of cataract. Ophthalmology 1983; 90: 352-64.

${ }^{2}$ Brown NAP, Bron AJ: Medical therapy in the prevention of cataract. Trans. Ophthalmol. Soc. UK. 1985; 104: 748-54.

${ }^{3}$ Cotlier E: Senile cataracts: Evidence for acceleration by diabetes and deceleration by salicylate. Can. J. Ophthalmol. 1981; 16: 113-18.

${ }^{4}$ Cotlier E, Fagadau W, Cicchetti DV: Methods for evaluation of medical therapy of senile and diabetic cataracts. Trans. Ophthalmol. Soc. UK. 1982; 102: 416-22.

${ }^{5}$ Crews SJ: Posterior subcapsular lens opacities in patients on long term corticosteroid therapy. $\mathrm{Br}$. Med. J. 1963; 1644-6.

${ }^{6}$ Pirie A: Colour and solubility of the proteins of human cataracts. Invest. Ophthalmol. 1968; 7:634-50.

${ }^{7}$ Brown N, Gardner RJM: Lowe Syndrome: Identification of the carrier state. In: The eye and inborn errors of metabolism. Ed: Bergsma D, Bron AJ, Cotlier EJP. 1976; 579-91.

${ }^{8}$ Clayton RM, Cuthbert J, Phillips CI, Bartholomew RS, Stokoe NL, Ffytche T, McK Reid J, Duffy J, Seth J, Alexander M: Analysis of individual cataract patients and their lenses: A progress report. Exp. Eye Res. 1980; 31: 553-66.

${ }^{9}$ Leibowitz HM, Krueger DE, Maunder LR, Milton RC, Kini MM, Kahn HA, Nickerson RJ, Pool J, Colton T, Ganley JP, Lowenstein JI, Dawber TR: The Framingham Eye Study Monograph. Surv. Ophthalmol. Suppl. 1980; 24: 350-64.

${ }^{10}$ Chylack LT: Classification of human cataractous change by the American co-operative cataract research group method. In: Human cataract formation. Ed: Nugent J, Whelan JJ. Pitman: London. (CIBA Foundation Symposium, 106.) 1984; 3-24.

${ }^{11}$ Hockwin D, Eckerskorn U, Schmidtmann W, Dragomirescu V, Korte I, Laser H: Epidemiological study of the association between lens cataract and case history, blood composition, and enzymes involved in lens carbohydrate metabolism. Lens Res. 1984; 2: 23-41.

${ }^{12}$ Chylack LT, Lee MR, Tung WH, Cheng HM: Classi- fication of human senile cataractous change by the American co-operative cataract research group method. 1. Instrument and technique. Invest. Ophthalmol. 1983; 24: 424-31.

${ }^{13}$ Chylack LT, Ransil BJ, White O: Classification of human senile cataractous change by the American cooperative cataract research group method. I. the association of nuclear colour (sclerosis) with extent of cataract formation, age and visual acuity. Invest. Ophthalmol. 1984; 25: 174 80.

${ }^{14}$ Chylack LT, White O, Tung WH: Classification of human cataractous change by the American co-operative cataract research group method. 2 . Staged simplification of cataract classification. Invest. Ophthalmol. 1984; 25: 166-73.

${ }^{15}$ Sparrow JM, Bron AJ, Brown NAP, Ayliffe W, Hill AH: Oxford clinical cataract classification and grading system. Int. Ophthalmol. 1986; 9: 20725.

${ }^{16}$ Brown N, Tripathi R: The loss of the anterior subcapsular clear zone of the lens. Prognostic significance in cataract formation. Trans. Ophthalmol. Soc. UK. 1974; 94: 29-45.

${ }^{17}$ Bron AJ, Brown NAP: Perinuclear lens retrodots: a role for ascorbate in cataractogenesis. $\mathrm{Br}$. J. Ophthalmol. 1987; 71: 86-95.

${ }^{18}$ Newhall SM, Nickerson D, Judd DB: Final report of the D.S.A. Subcommittee on the spacing of the Munsell colours. J. Opt. Soc. Am. 1943; 33: 385418.

${ }^{19}$ Sparrow JM, Ayliffe W, Hill A: (In preparation).

${ }^{20}$ Niesel Von P: Spaltlampenphotographie mit der Haag-Streit Spaltlampe 900. Ophthalmologica (Basel) 1966; 151: 489-504.

${ }^{21}$ Brown N: Quantitative slit-image photography of the lens. Trans. Ophthalmol. Soc. UK. 1972; 92: 303-17.

${ }^{22}$ Hockwin O, Dragomirescu V: Die ScheimpflugPhotographie des vorden Augenabschnittes. Zeitschrift fur Praktische Augenheilkunde. 1981; 2: 129-36.

${ }^{23}$ Chylack LT, Cheng HM, White O, Rosner B: Variances associated with objective documentation in vivo of human cataractous change with Topcon SL-45 and Neitz lens photography. Proc. Int. Soc. Eye Res. III 1984; p. 143 (abstract).

${ }^{24}$ West S, Rosenthal F, Newland HS, Taylor HR: A comparison of methods for typing and grading lens opacities for field surveys. Invest. Ophthal. Vis. Sci. 1985; 26 (3): 119 (Suppl).

${ }^{25}$ Chen SY, Chylack LT, White O: Topcon SL-45 Photography, a suitable technique for documenting nuclear, but not cortical cataractous changes in vivo. Invest. Ophthalmol. Vis. Sci. 1985; 26 (3): 119 (Suppl).

${ }^{26}$ Weiss JN, Rand LT, Gleason RE, Soledner HS: Laser light scattering spectroscopy of in vivo human lenses. Invest. Ophthalmol. Vis. Sci. 1984; 25: 594-8.

${ }^{27}$ Laing RA, Bursell SE: In vivo photomicrography of the crystaline lens. Arch. Ophthalmol. 1981; 99: 688-90. 
${ }^{28}$ Bron AJ, Matsuda K: Specular microscopy of the human lens. Trans. Ophthalmol. Soc. UK. 1981; 101: $163-9$.

${ }^{29}$ Fincham EF: Photographic recording of opacities of the ocular media. Br. J. Ophthalmol. 1955; 39: 85-9.

${ }^{30}$ Maclean H, Taylor CJ: An objective staging for cortical cataract in vivo aided by pattern-analysed computer. Exp. Eye Res. 1981; 33: 597602.

${ }^{31}$ Kawara T, Obazawa H, Nakano R, Sasaki M, Sakati $\mathrm{T}$ : Quantitative evaluation of cataractous lens opacities with retro-illumination photography. Jpn. J. Clin. Ophthalmol. 1979; 33: 21-6.

${ }^{32}$ Kawara T, Obazawa H: A new method for retroillumination photography of cataracious lens opacities. Am. J. Ophthalmol. 1980; 90: 186-9.

${ }^{33}$ Brown N: An advanced slit-image camera. Br. $J$. Ophthalmol. 1972; 56: 624-31.

${ }^{34}$ Brown N: Photographic investigation of the human lens and cataract. Surv. Ophthalmol. 1979; 23: 307-14.

${ }^{35}$ Brown N, Hungerford J: The influence of the size of the lens in ocular disease. Trans. Ophthalmol. Soc. UK. 1982; 102: 359-63.

${ }^{36}$ Hockwin O, Dragomirescu V, Laser H: Measurement of lens transparency of its disturbances by densitometric image analysis of Scheimpflug photographs. Graefes Arch. Clin. Exp. Ophthalmol. 1982; 219: 255-62.

${ }^{37}$ Chylack LT, White O, Sher L, Nodine M, Obazawa $\mathrm{H}$ : Objective measurement of cataractous growth in vivo. Invest. Ophthalmol. Vis. Sci. 1985; 26: 119.

${ }^{38}$ Brown N: Dating the onset of cataract. Trans. Ophthalmol. Soc. UK. 1976; 96: 18-23.

${ }^{39}$ Fleiss JL: Statistical methods for rates and proportions. 2nd edition. John Wiley and Sons (1981).

${ }^{40}$ Hall JN: Inter-rates reliability of wart rating scales. Br. J. Psychiat. 1974; 125: 248-55. 